IAC-15-A3,3B,8,x28808

\title{
DEVELOPMENT OF A MARSLANDER WITH CRUSHABLE SHOCK ABSORBER BY VIRTUAL AND EXPERIMENTAL TESTING
}

\author{
Silvio Schröder ${ }^{(1)}$ \\ B.Reinhardt ${ }^{(2)}$, C.Brauner ${ }^{(3)}$, I.Gebauer ${ }^{(4)}$ and R.Buchwald ${ }^{(5)}$
}

(1) DLR - German Aerospace Center - Institute of Space Systems, Robert-Hooke-Str. 7, D-28359 Bremen, Germany, silvio.schroeder@dlr.de

(2) University of Bremen, Bibliothekstr. 1, 28359 Bremen, Germany, Bianca.Reinhardt@spacex.com

(3) FIBRE - Faserinstitut Bremen e.V., Am Biologischen Garten 2, D-28359 Bremen, Germany, brauner@faserinstitut.de

(4) Fibretech composites GmbH, Am Lesumdeich 2, D-28719 Bremen, Germany, ingo.gebauer@fibretechcomposites.de

(5) Airbus DS GmbH, Airbus-Allee 1, D-28199 Bremen, Germany, robert.buchwald@airbus.com

\begin{abstract}
$\underline{\text { Abstract }}$
Since the beginning of space exploration, probes have been sent to other planets or moons with the associated challenge of landing on these bodies. For a soft landing several damping methods like landing legs or airbags have been used. A new and potentially less complex and lighter way to reduce the shock loads at touchdown is the use of a crushable shield underneath the lander platform. This crushable shield could be made for example out of an energy absorbing materials like an aluminum honeycomb core with a High Performance Polyethylene cover sheet. The design is particularly advantageous since no moving parts nor other mechanisms are required, thus making the shield very robust and fail safe. The only mission that is currently planned to use this technique is the ESA-mission "ExoMars" which is planned to start in 2016.

The development of such a crushable shock absorber implies and requires assessment of materials, manufacturing processes, the setup of a numerical simulation and the experimental validation in a test lab. In an independent research project (Marslander1) a representative engineering mockup of the landing platform has been build and tested at the Landing \& Mobility Test Facility (LAMA) to support the numerical simulation model with experimental data. The simulations are based on the explicit Finite Element Method, which discretizes the structure into a defined number of elements, such that each element is assigned a set of equations describing the material properties and applied loads. The goal is to generate a simplified but still accurate model to predict landing scenarios by running Monte Carlo simulations.
\end{abstract}

Results of the above stated development and testing processes will be presented and discussed in this paper.

\section{BACKGROUND}

The DLR department of Landing- and exploration technology is investigating miscellaneous landing system concepts to provide a reliable, save and lightweight landing system for a specific landing mission. The assessment is driven by the mission requirements and the local environment.

Past projects mostly used landing leg designs, which have the disadvantage of being heavy and need to be deployed which require extra mechanisms that could fail.

The advantage on the other side is a high landing stability and the chance of generating ground clearance between Lander platform and local terrain. For missions where no clearance is needed and where the lander is comparatively flat (low CoG), a landing leg system is not mandatory.
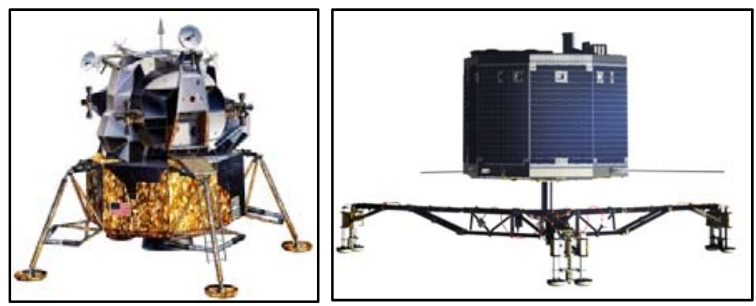

Fig. 1: left: Apollo Lunar Module [1], right: Philae Lander [2]

A new and potentially less complex and lighter way to reduce the shock loads at touchdown is the use 
of a crushable shield underneath the lander platform. This crushable shield is made out of an aluminum honeycomb core with a High Performance Polyethylene cover sheet.

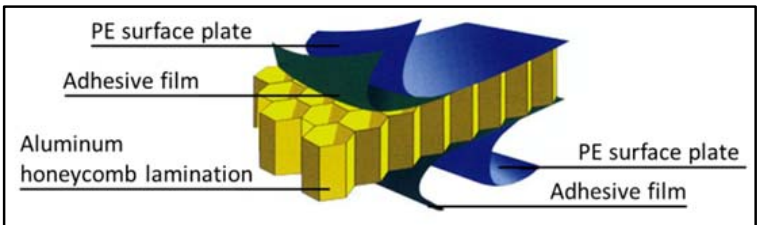

Fig. 2: Typical aluminum honeycomb panel

\section{DESIGN}

To study an example with a crushable platform, this study is orientated on the ESA-mission "ExoMars", where a European lander will land on Mars in 2016. [3]

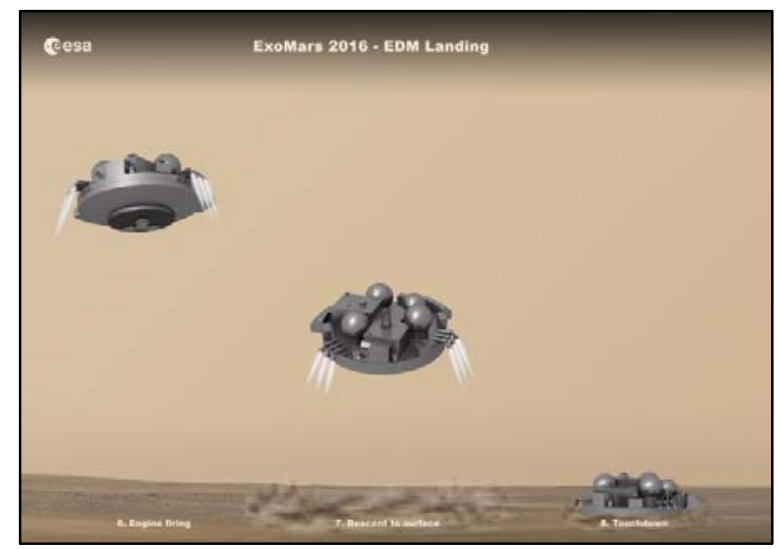

Fig. 3: ExoMars lander Schiaparelli

The shape of the shock absorbing structure underneath the platform is calculated for the effective mass acting on it. The closer to the edge the less force is applied. The mass distribution can be calculated by

$$
m_{r}=\frac{1}{\left(\frac{b^{2}}{I}+\frac{1}{m}\right)}
$$

where $b$ is the distance from stone to center point of platform, $I$ the platform inertia and $m$ the platform mass. This result can be inserted in the equation for the required honeycomb thickness of landing on a flat terrain covered with a hemispherical stone:

$$
r_{s}=\sqrt[3]{\frac{3 E_{\text {kin }}}{2 \pi \cdot \sigma_{\text {crush }}}}
$$

with

$$
E_{\text {kin }}=1 / 2 \cdot m_{r} \cdot v^{2}
$$

Hereby is $v$ the vertical touchdown velocity and $\sigma_{\text {crush }}$ the crush strength of the honeycomb. For a given mission profile, this results in the following honeycomb height:

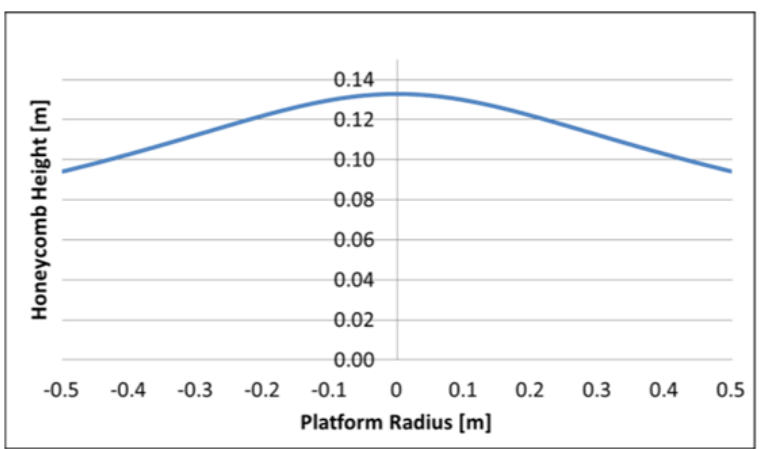

Fig. 4: Calculated honeycomb height w.r.t. the distribution of mass and platform radius

The choice of the facesheet material has been verified by impact tests on component level. As previous investigations have shown synthetic fibers like Kevlar 49 and Dyneema ${ }^{\circledR}$ have the highest tensile strength and show the best performance. [4]

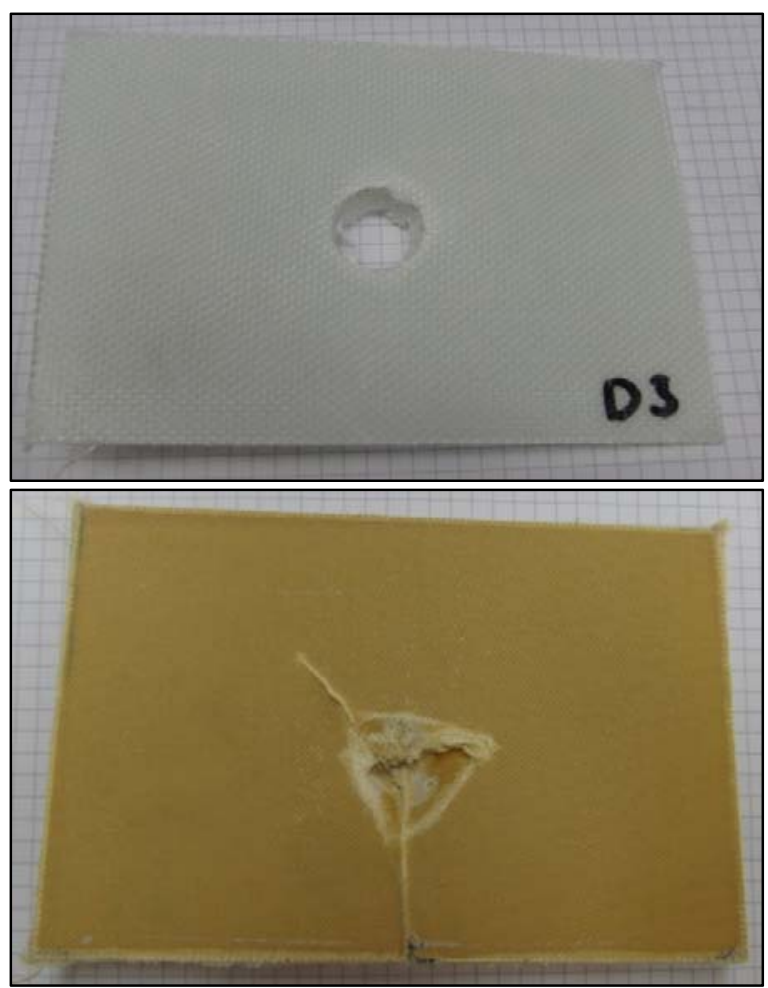

Fig. 5: Fracture pattern of Dyneema ${ }^{\circledR}$ (top) and Kevlar 49 (bottom) [5]

The results of the comparing material tests showed clear advantages of Dyneema ${ }^{\circledR}$. It is ca. $30 \%$ lighter, 
has twice the strain of rupture than Kevlar 49 and collapses more ductile. By this reason this material has been chosen as surface cover sheet.

The derived model has the same mass and a similar geometry as the Schiaparelli lander.

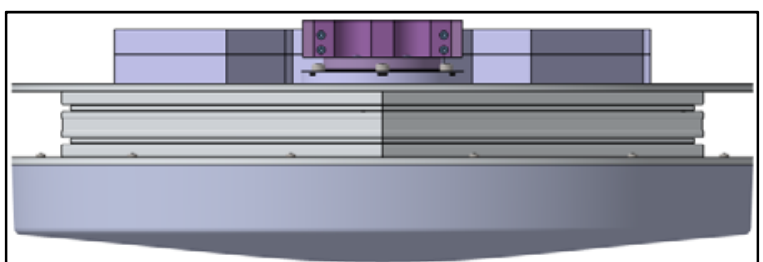

Fig. 6: 3D CAD model of the Marslander [5]

\begin{tabular}{ll}
\hline Mass & $290 \mathrm{~kg}$ \\
Moment of Inertia & $\mathrm{I}_{1}=64 \mathrm{kgm}^{2}$ \\
& $\mathrm{I}_{2}=40 \mathrm{kgm}^{2}$ \\
& $\mathrm{I}_{3}=40 \mathrm{kgm}^{2}$ \\
\hline Center of Mass & $91 \mathrm{~mm}$ above crash material \\
Diameter & $1000 \mathrm{~mm}$ \\
Core Material & $3 / 16-5056-0.0007-1.0$ \\
& perforated (Plascore) \\
Facesheet & $1.41 \mathrm{~mm}$ (quasi-isotropic \\
& layup of 4 plies Dyneema $®)$ \\
\hline
\end{tabular}

Table 1: Properties of Marslander [5]

\section{TEST SETUP}

To get feasible data for the simulation verification, real hardware tests are needed. For this reason a test setup has been constructed for the Landing \& Mobility Test Facility (LAMA) [6] consisting of the LAMA robot (1), the test specimen (2) and the surface platform (3, see Fig. 7).

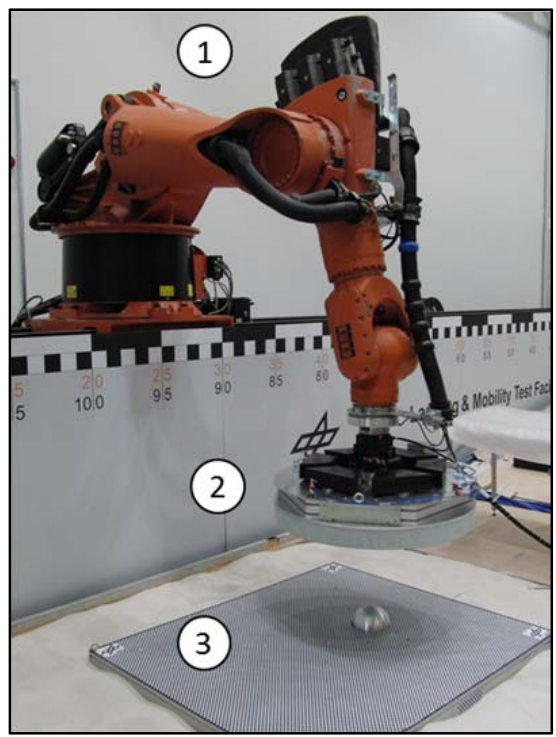

Fig. 7: DLR LAMA facility with test setup

\section{III.I. LAMA Facility}

The basic configuration of the LAMA facility consists of a 6-axis industrial robot system KR500 (1) with an additional rail track system (2) for horizontal movement $(\max .2 \mathrm{~m} / \mathrm{s}$ in every direction), a forcetorque sensor (3) on the hand flange for a sensor driven mode, a controller (4) to set up, control and maintain the experiment conditions and a $10 \times 4 \mathrm{~m}^{2}$ soil bin (5) containing the planetary soil simulant. All elements are integrated into a test cell (6) which provides the necessary infrastructure.

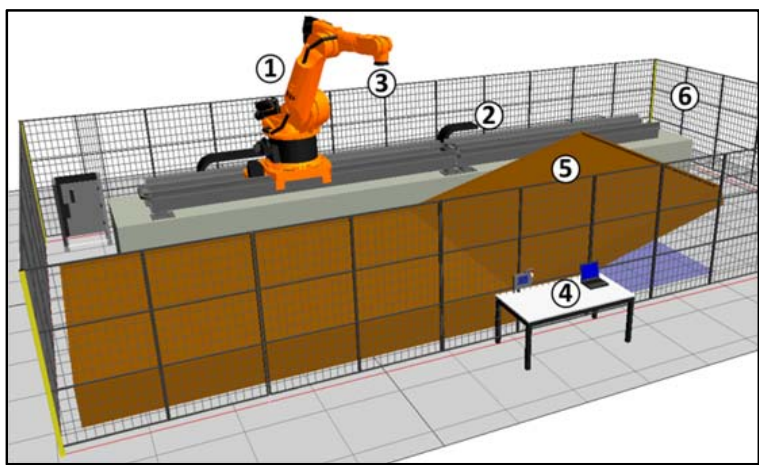

Fig. 8: Components of LAMA [6]

The LAMA facility is constructed to support any kind of landing or surface mobility scenarios either in a coupled weight-offloading mode (to compensate the lower gravity on other planets) or with a pneumatic gripper to release the lander (up to $500 \mathrm{~kg}$ ) in a free fall, as in this case.

A central data acquisition system (DAQ) collects all signal from the sensors as well as the robot data (position, forces,...)

\section{III.II. Test Specimen}

The Test specimen is divided into two parts. The upper level comprises all sensors (5 three-axisaccelerometers and an Inertial Measurement Unit IMU), the suspension for the gripper release mechanism and the mass-dummies to achieve the $290 \mathrm{~kg}$ platform mass. The lower level is the crash platform itself. 

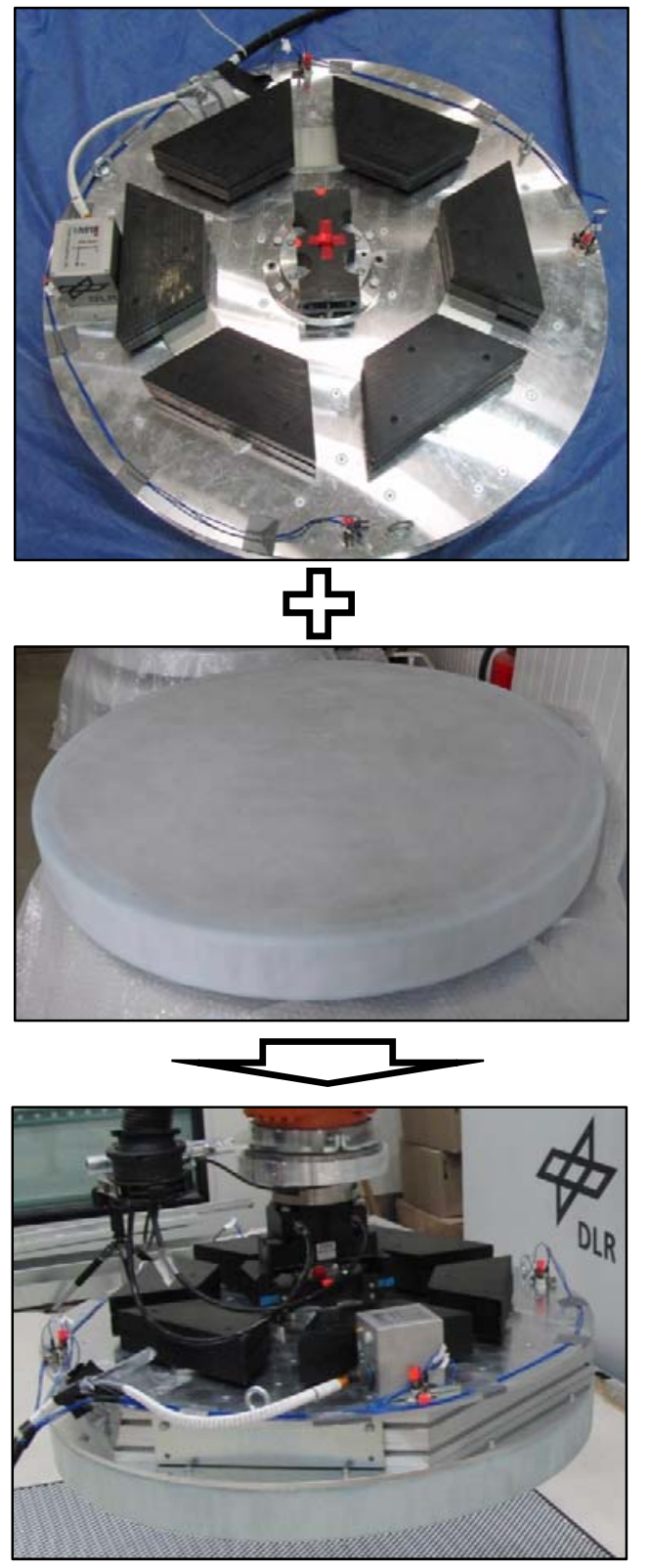

Fig. 9: Marslander instrument carrier (top), crash platform (middle) and assembled Lander (bottom)

12 crushable platforms have been produced (one for each test run) and were subsequently attached to the upper structure.

\section{III.III. Surface Platform}

The surface platform serves as a reference plane and is equipped with force sensors in the four foots and one additional under the artificial stone, with which the impact load can be determined. Due to the destructive deformation of the crash platform the force cannot be measured on the lander side and the platform acts as a scale by adding all four force sensors together.

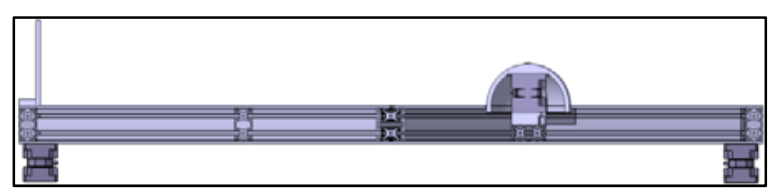

Fig. 10: section cut of the surface platform

\section{TEST EXECUTION}

The test scenarios comprise five particular scenarios, including vertical and horizontal velocities, touchdowns at inclinations of 10 degrees and an impact object in form of a sphere, as presented in Fig. 11. Overall 12 drop tests have been performed (see Table 2).

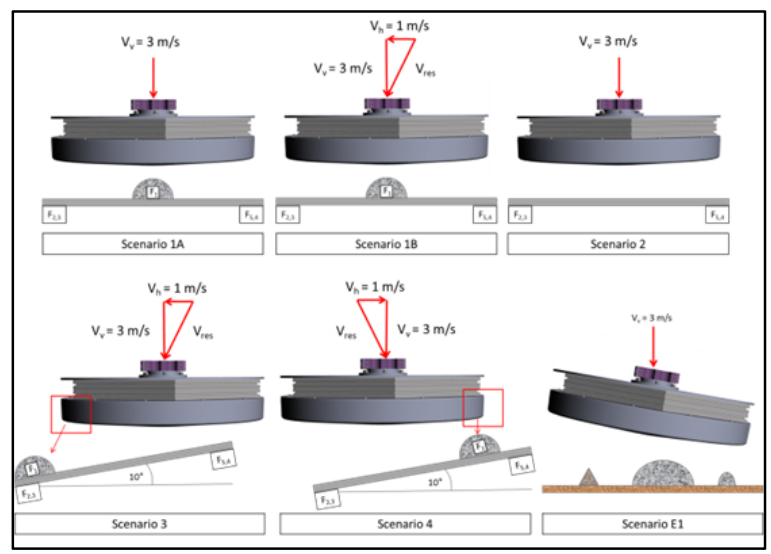

Fig. 11: Illustration of test scenarios [7]

\begin{tabular}{|c|c|c|}
\hline \begin{tabular}{|l|} 
Scenario \\
\end{tabular} & Test ID & Description \\
\hline \multirow{3}{*}{$\mathbf{1 A}$} & 1 & \multirow{3}{*}{$\begin{array}{l}\text { - Vertical impact on rigid stone } \\
\text { and horizontal ground } \\
\text { - Impact velocity: } 3 \mathrm{~m} / \mathrm{s}\end{array}$} \\
\hline & 2 & \\
\hline & 3 & \\
\hline 2 & 4 & $\begin{array}{l}\text { - Vertical impact on horizontal } \\
\text { ground } \\
\text { - Impact velocity: } 3 \mathrm{~m} / \mathrm{s}\end{array}$ \\
\hline \multirow{2}{*}{ 1B } & 5 & \multirow{2}{*}{$\begin{array}{l}\text { - Transversal impact on rigid } \\
\text { stone and horizontal ground } \\
\text { - Vertical velocity: } 3 \mathrm{~m} / \mathrm{s} \\
\text { - Horizontal velocity: } 1 \mathrm{~m} / \mathrm{s} \\
\end{array}$} \\
\hline & 6 & \\
\hline \multirow[b]{2}{*}{3} & 7 & \multirow{2}{*}{$\begin{array}{l}\text { - Transversal impact on inclined } \\
\text { ground against stone } \\
\text { - Vertical velocity: } 3 \mathrm{~m} / \mathrm{s} \\
\text { - Horizontal velocity: } 1 \mathrm{~m} / \mathrm{s} \\
\text { - Inclination angle: } 10^{\circ}\end{array}$} \\
\hline & 8 & \\
\hline 4 & 9 & $\begin{array}{l}\text { - Transversal impact on inclined } \\
\text { ground against stone }\end{array}$ \\
\hline
\end{tabular}




\begin{tabular}{|c|c|l|}
\hline & 10 & $\begin{array}{l}\text { - Vertical velocity: } 3 \mathrm{~m} / \mathrm{s} \\
\text { - Horizontal velocity: } 1 \mathrm{~m} / \mathrm{s} \\
\text { - Inclination angle: }-10^{\circ}\end{array}$ \\
\hline E1 & $\mathbf{1 1}$ & $\begin{array}{l}\text { - Tilted impact on rigid stone and } \\
\text { sand } \\
\text { - Vertical velocity: } 3 \mathrm{~m} / \mathrm{s}\end{array}$ \\
\hline E2 & $\mathbf{1 2}$ & $\begin{array}{l}\text { - Vertical impact on rigid stone } \\
\text { and rigid horizontal ground } \\
\text { - Impact velocity: } 3 \mathrm{~m} / \mathrm{s}\end{array}$ \\
\hline
\end{tabular}

Table 2: Description of test scenarios

A typical drop sequence with horizontal velocity is depicted in Fig. 12.

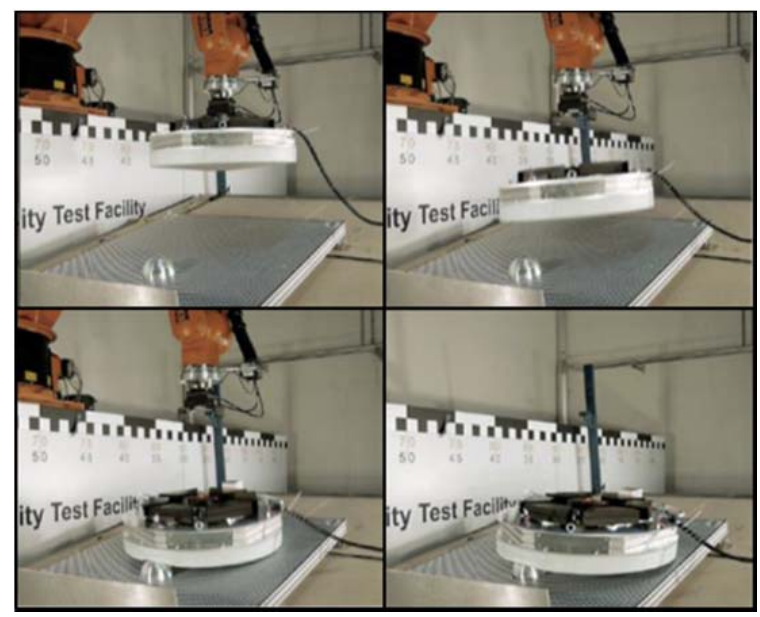

Fig. 12: Example of a test sequence (scenario 3) [7]

\section{TEST RESULTS}

For all tests several high-speed cameras recorded the drops visually while the force and acceleration data gave detailed information about the loads at certain time steps. The total penetration depth caused by impact was determined for each test specimen by measuring the remaining undamaged honeycomb height of the cross sections.
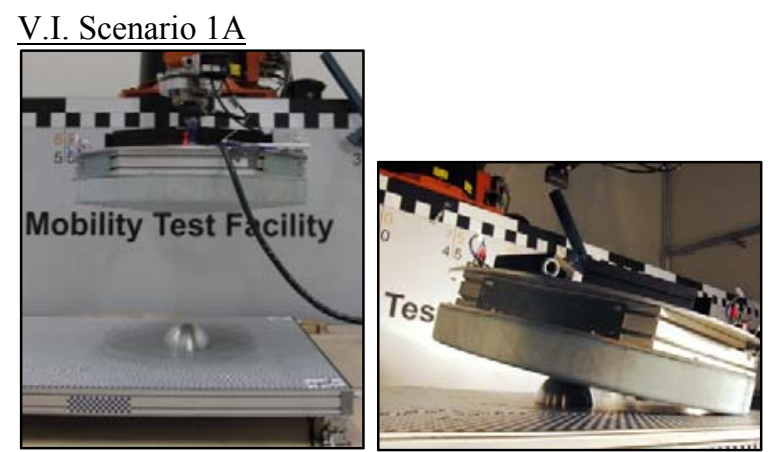

Fig. 13: Drop test Scenario 1A
The first scenario showed different damages after the first two test runs why a third run was included. The platform showed in two cases a rupture of the facesheet and in one case only a delamination.

A further observation was the deformation of the surface platform due to the impact shock. This elastic characteristic could be a determining boundary factor influencing the demonstrator impact. In order to assess the total effect of ground plate elasticity an additional test (test E2) of 1A has been implemented in which the force sensors have been removed and the ground plate was placed upon damping material (sand) to ensure a nearly rigid ground.

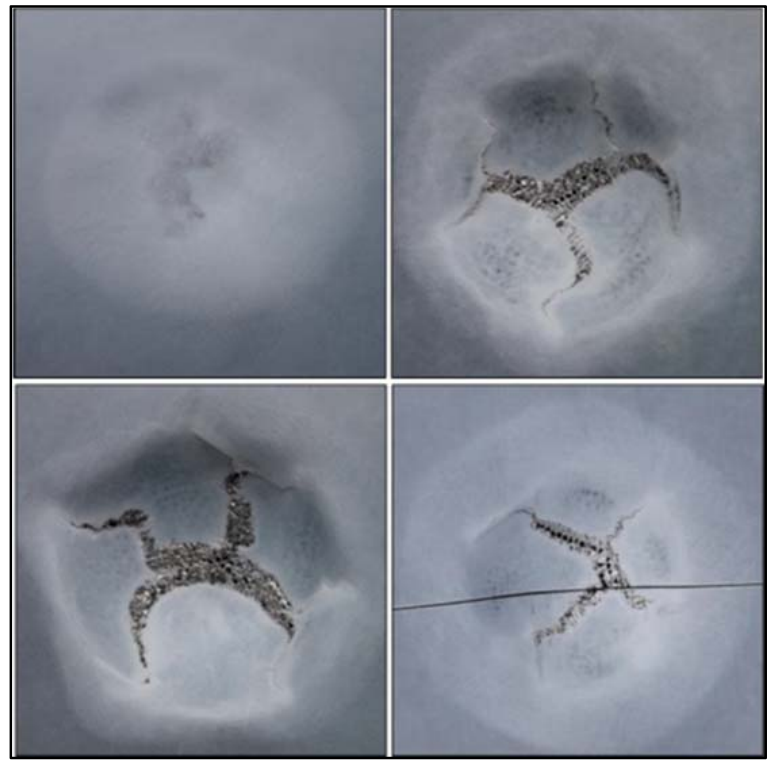

Fig. 14: Impacted area of Test 1 (top, left), 2 (top, right), 3 (bottom, left) and E2 (bottom, right)

This difference between the first test and the second and third, suspects the cause in manufacturing procedure, in which the fiber reinforced material might be taken from different batches.

For the determination of penetration depth, all test specimens are sawed in center to measure the imprint, or rather the remaining block length of honeycomb of the cross sections.

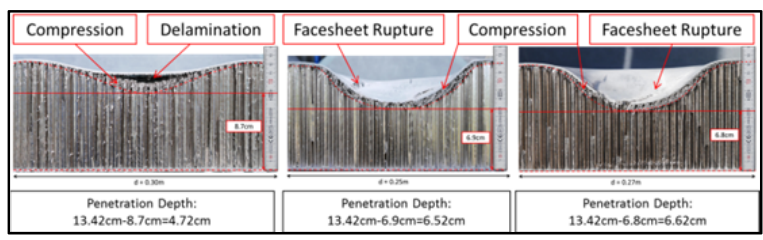

Fig. 15: Comparison of cross sections of impacted area of Test 1 (left), 2 (center) and E2 (right) 
Comparing the cross sections, Test 1 shows a clear delamination in the center between the facesheet and honeycomb, caused by the elongation of laminate in the elastic range while the honeycomb is compressed during impact and remains compressed after springback, leading to the delamination.

If a facesheet rupture occurs as presented for Test 2, 3 and 12, the facesheet parts are compressed against the honeycomb and remain compressed after release. This leads to a much larger depth of penetration, in this case an increase of about $45 \%$ with respect to Test 1 . In any case the penetration depths are still within the constraints of $75 \%$ block length, which equals an uncompressed honeycomb height of $33 \mathrm{~mm}$. Test 2, 3 and 12 do not show any significant difference in penetration depth nor in the failure characteristics of the facesheet.
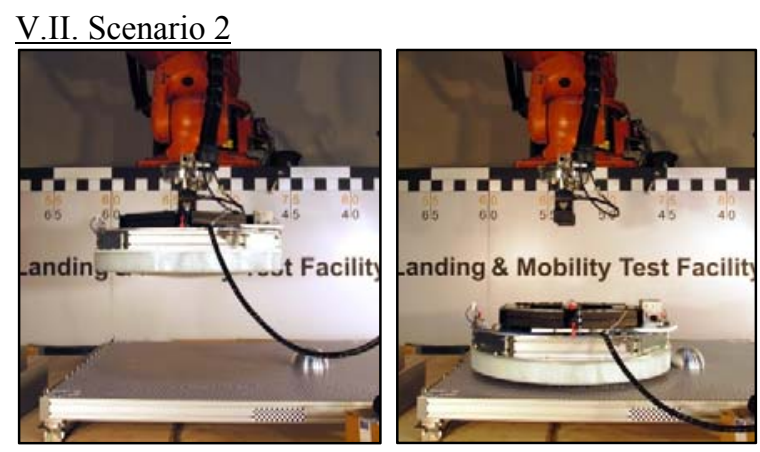

Fig. 16: Drop test Scenario 2

In the second scenario only one drop has been done, since this is the one with the least error probability w.r.t. disturbances in the test setup and performance. (vertical drop on a plain ground). The test specimen showed only minor deformation, as can be seen in Fig. 17.

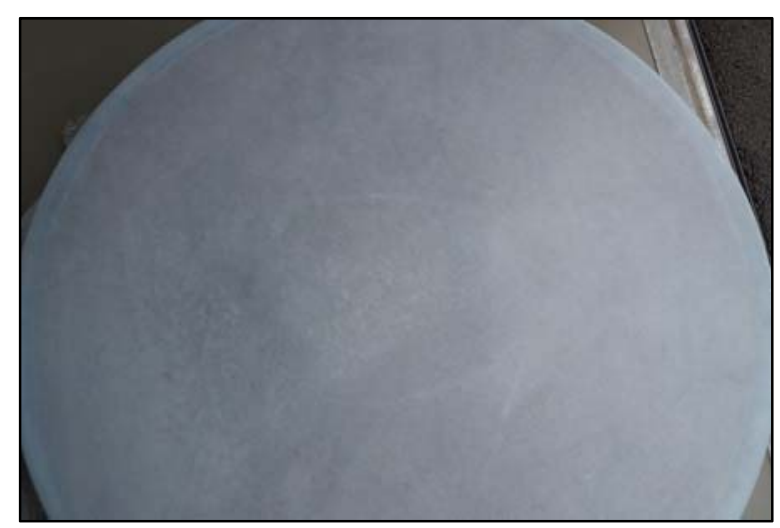

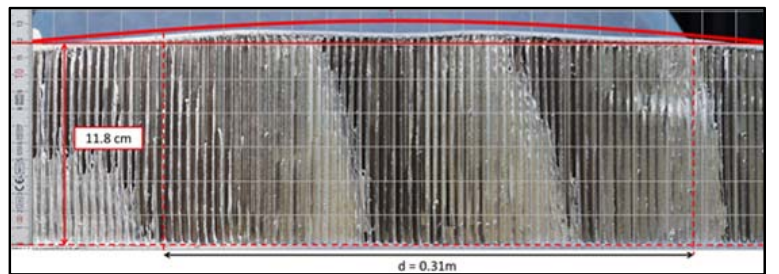

Fig. 17: Deformation and cross section of scenario 2

The cross section does not show any sign of delamination or other facesheet failure and the honeycomb compresses by a minor value of roughly $1.54 \mathrm{~cm}$ in the center of platform. As this test is the one with the least deformation the deceleration has the highest value of $28 \mathrm{~g}$, as can be seen in Fig. 18. This is far below the requirement of $<60 \mathrm{~g}$, although it has to be stated that the sensors had low-pass filter of $50 \mathrm{~Hz}$, so only quasi-static values could be measured. Therefore the real shock-acceleration is probably a little bit higher.

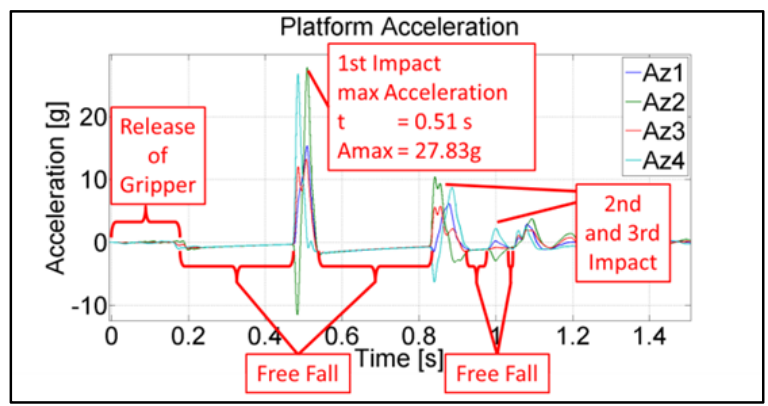

Fig. 18: Vertical accelerations of the lander

A few other effects can also be seen from this graph. The release time of the gripper can be determined to $187 \mathrm{~ms}$. Then a free fall time occurs until first impact. Afterwards the platform is springbacking several times until the platform comes to rest, which indicates certain elasticity in the system. This so-called coefficient of restitution $C_{R}$ can be calculated from the two free fall heights:

$$
C_{R}=\sqrt{\frac{h_{2}}{h_{1}}},
$$

where $h_{1}$ is the initial drop height $\left(h_{l}=0.459 \mathrm{~m}\right)$ and $h_{2}$ is the bounce height, which can be calculated from the equation of motion

$$
h_{2}=\frac{1}{2} \cdot g \cdot t^{2}
$$

where $g$ is the earth gravitation constant and $t$ the time of falling downwards, which is half of the total free fall time $\Delta t$ 


$$
\Delta t=0.823 \mathrm{~s}-0.541 \mathrm{~s}=0.282 \mathrm{~s} .
$$

The Marslander demonstrator resides at maximum height at time $\Delta t / 2$, thus the height $h_{2}$ can be described as

$$
h_{2}=\frac{1}{2} \cdot g \cdot\left(\frac{\Delta t}{2}\right)^{2}=0.100 m
$$

Inserting $h_{2}$ into (4) results in

$$
C_{R}=\sqrt{\frac{h_{2}}{h_{1}}}=\sqrt{\frac{0.100 m}{0.459 m}}=0.46 .
$$

This factor is a measure of how much kinetic energy is dissipated due to deforming of the structure. The lower this factor the more energy is dissipated. In Table 3 each test without horizontal velocity is compared to each other.

\begin{tabular}{ccccc}
\hline $\begin{array}{l}\text { Test Spring-back Coefficient of } \\
\text { No. }\end{array}$ & $\begin{array}{c}\text { Measured } \\
\text { time } \Delta \mathbf{t}[\mathbf{s}] \\
\text { Restitution } \\
\mathbf{C}_{\mathbf{R}}\end{array}$ & $\begin{array}{c}\text { Facesheet } \\
\text { Force }[\mathbf{k N}]\end{array}$ & $\begin{array}{c}\text { ruptured } \\
\text { Fonh }\end{array}$ \\
\hline $\mathbf{1}$ & 0.287 & 0.47 & 41.4 & No \\
$\mathbf{2}$ & 0.111 & 0.18 & 31.8 & Yes \\
$\mathbf{3}$ & 0.137 & 0.22 & 29.2 & Yes \\
$\mathbf{4}$ & 0.282 & 0.46 & 42.9 & No \\
$\mathbf{1 2}$ & 0.073 & 0.12 & 37.3 & Yes \\
\hline
\end{tabular}

\section{Table 3: Comparison of Coefficient of Restitution} for tests without horizontal velocity

It is clearly visible that for impacts without facesheet rupturing $C_{R}$ is more than twice as high as the others, which means more energy is dissipated with facesheet rupture than just with delamination. Second, an influence of the stiff surface platform (Test 12) compared to the more flexible one (Test 2 and 3 ) is observable, which indicates that the surface platform stores a fraction of the kinetic energy in elasticity and gives it back for the spring-back, as it also can be seen in the lower peak crash forces.
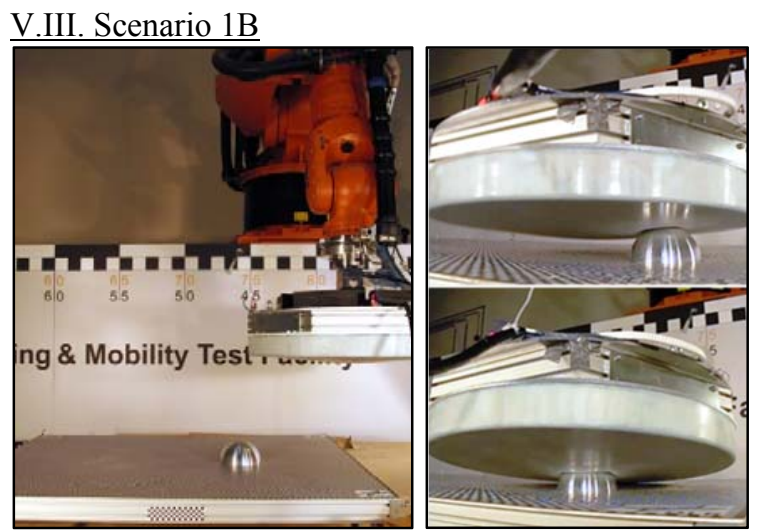

Fig. 19: Drop test scenario 1B, initial state (left), point of impact of Test 5 (top, right) and 6 (bottom, right)

As can be seen, those two test run differ from their first point of contact. Due to the adding of a horizontal velocity w.r.t. Scenario 1A an uncertainty occurs from the initial release to impact point. In the second test run this offset from the center point has been added to the path planning of the robot, so that in the second run the platform hit the sphere in its center.
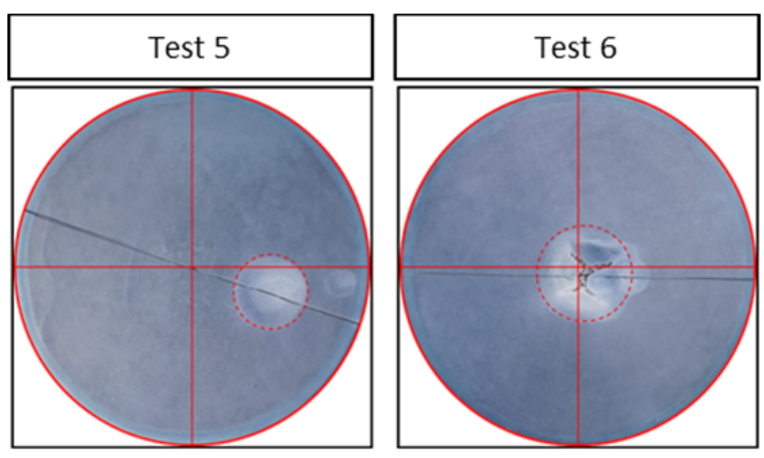

Fig. 20: Comparison of impact point of Test 5 and 6

Due to the reduced mass acting during impact, Test 5 shows no facesheet rupture, but a second impact circle and sidewall crushing in the front area, due to the impact on ground. 


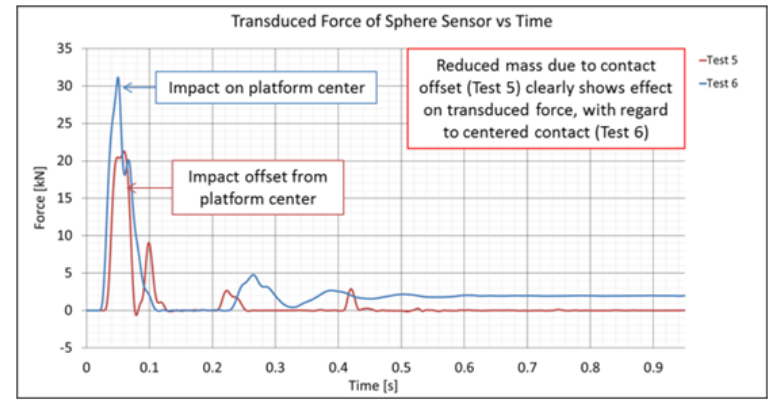

Fig. 21: Transduced z-force of sphere for Test 5 and 6 [7]

In Fig. 21 the maximum forces are plotted, where Test 5 has a clear lower force level than Test 6 which corresponds to the theory of the reduced mass, due to offset from center point (eq. 1). The distance of the first impact point from the center is about $22 \mathrm{~cm}$, which leads to a reduced mass of $212 \mathrm{~kg}$. A qualitative analysis is given in Table 4.

\begin{tabular}{lll||l}
\hline & Test 5 & Test 6 & \% \\
\hline $\mathbf{F}_{\max }[\mathbf{k N}]$ & 21.28 & 31.15 & 68.3 \\
$\mathbf{m}_{\mathbf{r}}[\mathbf{k g}]$ & 212 & 290 & 73.1 \\
\hline
\end{tabular}

Table 4: Comparison of $z$-forces and reduced mass of Test 5 and 6

The two percentage values in the right column are very similar (with only $5 \%$ difference), which shows the correctness of the assumption of the reduced mass.

\section{V.IV. Scenario 3}
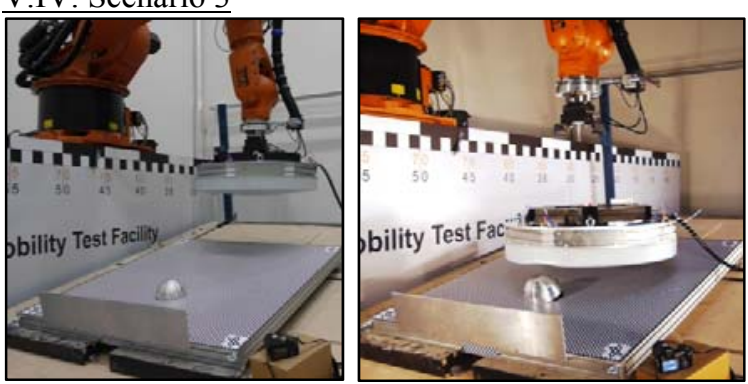

Fig. 22: Drop test Scenario 3

In Scenario 3 an inclined plain is added (in comparison to Scenario 1B) with motion downwards. In both test runs the sphere unhitched due to the high lateral force acting on it, leading to the loss of the sphere force signals.

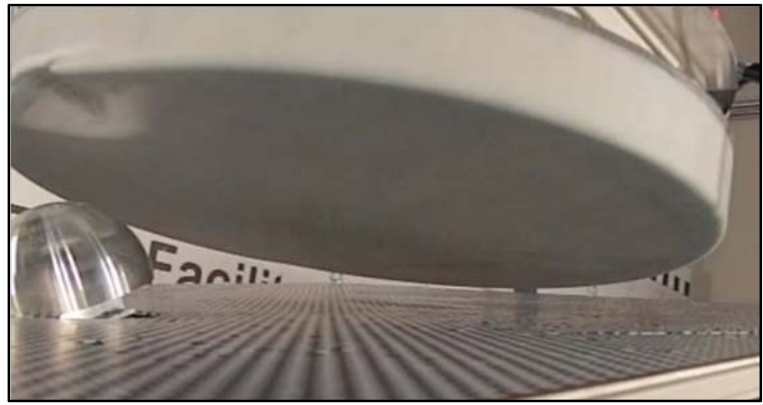

Fig. 23: Unhitching of sphere (Test 7)

However, visual inspection observation could lead to meaningful conclusions.
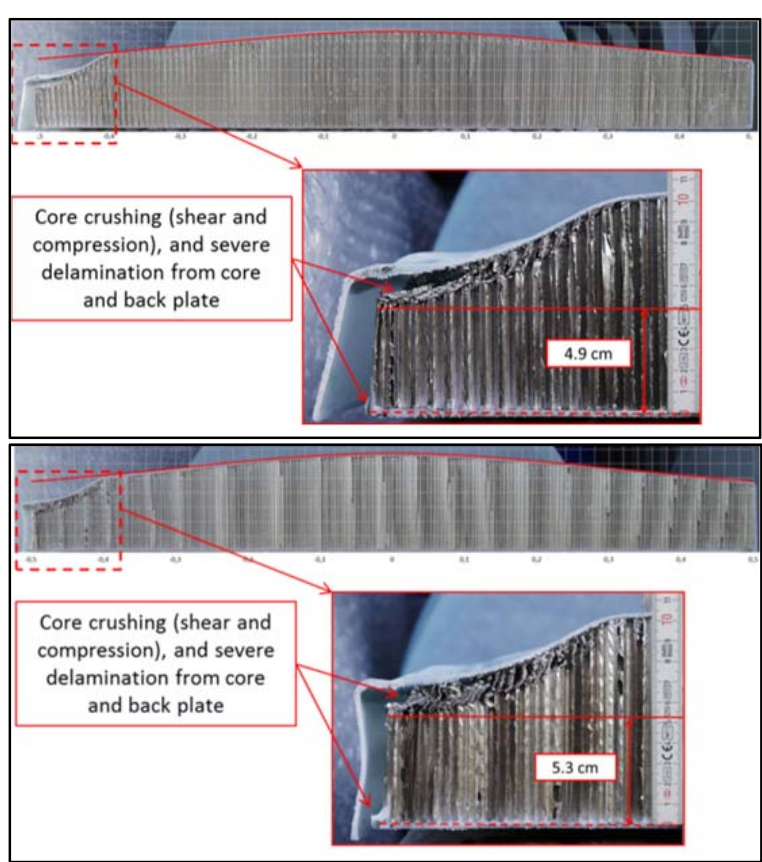

Fig. 24: Comparison of cross sections showing the deformations in the impacted area for Test 7 (top) and 8 (bottom)

Generally both tests show similar failure features. Due to the lateral impact the facesheet elongates and delaminates during spring-back from honeycomb core and the subjacent back plate. A clear shear failure is visible in core material, being severe at the edges and moderate towards the center, in combination with core compression as well. Beside the fact, that no major damage occurs, therefore stating the platform design is feasible for such scenario. 
V.V. Scenario 4

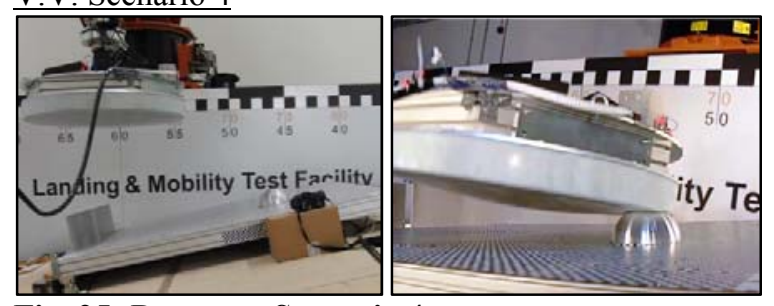

Fig. 25: Drop test Scenario 4

In contrast to Scenario 3, the impact occurs upward the slope. In this case the sphere does not unhitch, because of a stronger connection between sphere and platform. In any case Test 9 and Test 10 of Scenario 4 showed very good reproducibility, regarding impact indentation depth and area, such as force progression in $\mathrm{x}, \mathrm{y}$ and $\mathrm{z}$-direction.

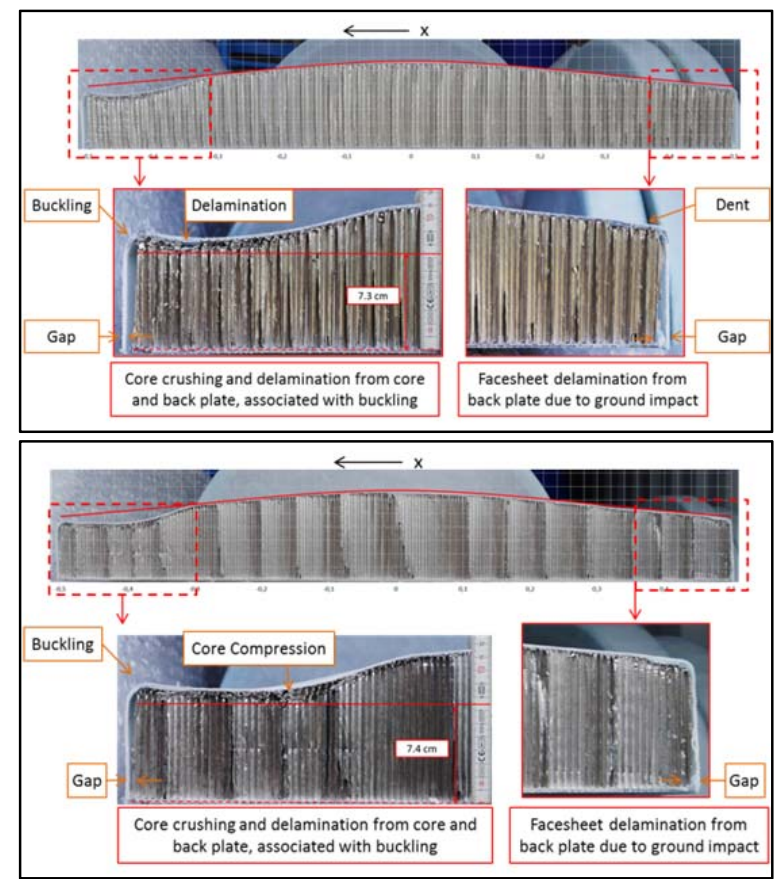

Fig. 26: Cross section showing the deformation of impacted areas for Test 9 (top) and 10 (bottom)

Generally two impacts occurred, the first one being by contact with the sphere and the second by contact with the ground plate. The first impact causes the facesheet to delaminate from honeycomb and back plate, with a clear gap between side facesheet and back plate due to the spring-back behavior of the laminate (marked as gap in the figure). Test 9 additionally showed buckling in facesheet laminate due to the shear strain. The honeycomb showed shear failure in the laterally impacted area but barely any compression in areas of the second impact towards the ground plate. Instead the sandwich structure delaminates from the back plate, therefore failing in this region before the honeycomb could be affected. This suggests to initially leaving a gap between back plate and sandwich structure in future designs, in order to avoid such failure and to maintain the bearing pressure, and respectively the energy absorbance, within the honeycomb.

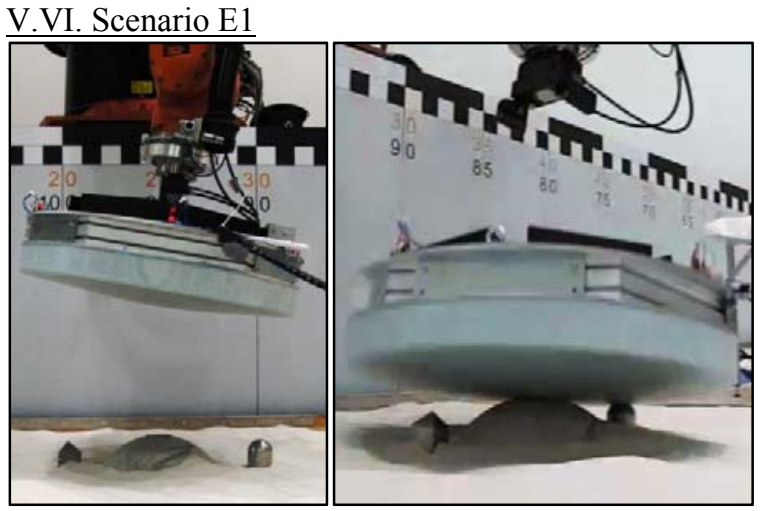

Fig. 27: Drop test scenario E1

Scenario E1 was performed as an extra case, in order to prove the feasibility of platform when impacted onto multiple impact objects of different sizes and shapes, with a soft ground, such as sand.

The video analysis showed a simultaneous contact on the two spherical obstacles and no interaction between platform and pyramid impactor, instead the platform steadies after the impact on the large stone, resting upon it in the final stage.

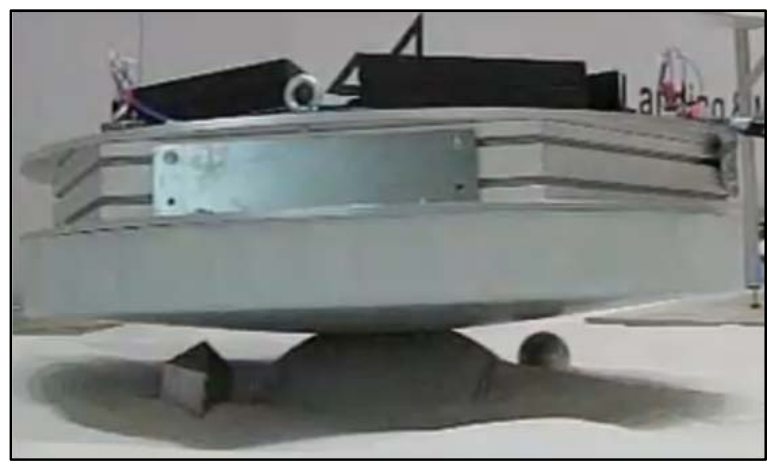

Fig. 28: End state of Scenario E1

Since the first impact is offset about $39.3 \mathrm{~cm}$ from the center of platform, the entire mass is not acting upon this point, but instead a reduced mass, which leads to a decreased kinetic energy at touchdown and a lower deformation. 


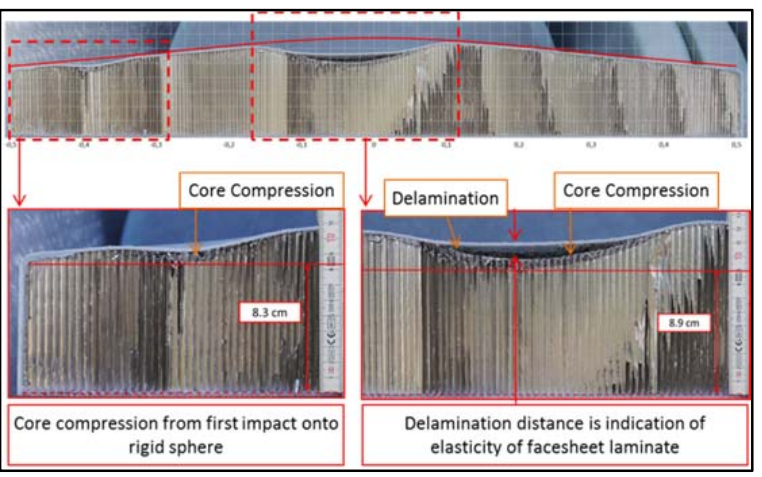

Fig. 29: Cross section showing the deformation in the impacted area for Test 11

Given these observations the platform is indeed feasible for multiple impact objects of different sizes, in addition with an angle offset of the platform itself.

\section{V.VII. Orientation angles at time of impact}

The test video recordings have shown generation of angular velocities during free fall in all scenarios, caused by an unbalanced release of the robot. Since, this has strong effects on the simulation with LS-Dyna, the touchdown angles and velocities need to be determined.

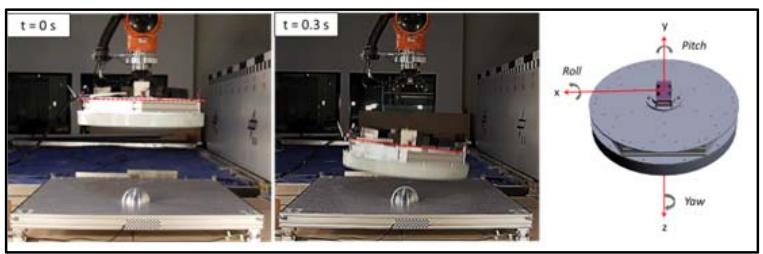

Fig. 30: Generation of angular velocity during release from initial state (left) up to impact (center) and description of angles (right)

The orientation angles and the respective angular velocity at time of impact could be determined by evaluating the IMU data. In Table 5 the results for the four scenarios which are validated by simulation are shown.

\begin{tabular}{ccc}
\hline Scenario & $\begin{array}{c}\text { Orientation angle and angular velocity } \\
\text { at time of impact }\end{array}$ \\
\hline \multirow{3}{*}{$\mathbf{1 A}$} & Roll: $7.8^{\circ}$ & $\omega(\mathrm{x}):-0.1 \% \mathrm{~s}$ \\
& Pitch: $1.0^{\circ}$ & $\omega(\mathrm{y}): 19.6^{\circ} / \mathrm{s}$ \\
& Yaw: $0.2^{\circ}$ & $\omega(\mathrm{z}):-1.2^{\circ} / \mathrm{s}$ \\
\multirow{2}{*}{$\mathbf{2}$} & Roll: $6.7^{\circ}$ & $\omega(\mathrm{x}): 16.3^{\circ} / \mathrm{s}$ \\
& Pitch: $1.2^{\circ}$ & $\omega(\mathrm{y}):-0.2^{\circ} / \mathrm{s}$ \\
& Yaw: $0.2^{\circ}$ & $\omega(\mathrm{z}):-1.1^{\circ} / \mathrm{s}$ \\
\hline
\end{tabular}

\begin{tabular}{ccc}
\hline \multirow{4}{*}{$1 B$} & Roll: $7.3^{\circ}$ & $\omega(\mathrm{x}): 20.5^{\circ} / \mathrm{s}$ \\
& Pitch: $2.4^{\circ}$ & $\omega(\mathrm{y}): 0.7^{\circ} / \mathrm{s}$ \\
& Yaw: $0.1^{\circ}$ & $\omega(\mathrm{z}):-1.0^{\circ} / \mathrm{s}$ \\
4 & Roll: $7.2^{\circ}$ & $\omega(\mathrm{x}): 16.7^{\circ} / \mathrm{s}$ \\
& Pitch: $1.7^{\circ}$ & $\omega(\mathrm{y}):-0.0^{\circ} / \mathrm{s}$ \\
& Yaw: $-0.6^{\circ}$ & $\omega(\mathrm{z}):-1.0^{\circ} / \mathrm{s}$ \\
\hline
\end{tabular}

Table 5: Orientation angle and angular velocity at time of impact [7]

\section{V.VIII. Summary of test results}

In summary the test setup worked well, all data have been recorded (except for Scenario 3), although due to the Butterworth-Filter of $50 \mathrm{~Hz}$ only quasi-static values could be obtained. The opening of the robot gripper generated tilted angles of the platform at touchdown which need to be considered in the simulation, as well as the bending of the surface platform.

After one trial run (Test 5) all other tests with horizontal velocity met their predetermined touchdown positions, confirming the good reproducibility of the robotic system. The unhitching of the sphere (Scenario 3) caused a lack of sphere sensor data, but could be repaired for the next scenarios.

Critical shear failure during lateral impact cases has not been observed, instead the honeycomb crashed and compressed in reasonable extent.

\section{VIRTUAL TESTING}

To support the experimental tests, numerical simulations (LS-Dyna and LS-PrePost) have been performed, first to provide general touchdown predictions and second for validation of the experimental results for future landing scenarios. The whole development of the simulation starting from component level, over assembly level to the actual lander design is described in detail in [8]. Here a summary is given of the obtained results.

\section{VI.I. Simulation setup}

In a first step the sandwich made out of a honeycomb core and facesheet cover is fractionized to the component level and subsequently correlated with hardware tests [9],[10]. All elements have been studied with regard to their physical behavior and hourglass energy [11].

Therefore the honeycomb core material is homogenized using solid elements. For the simulation the MAT126-3 ("Toyota-Model") has been used with element type 1 showing the best results. 


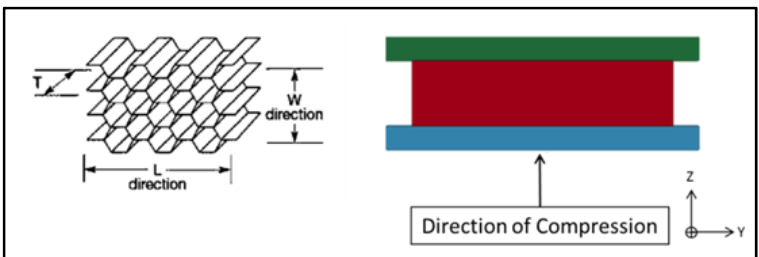

Fig. 31: Model of the honeycomb for compression test

The facesheet simulation has been done with the MAT54 (Material Enhanced Composite Damage) and a material card of Kevlar 49. The element formulation 16 has been chosen for further calculations on assembly level.

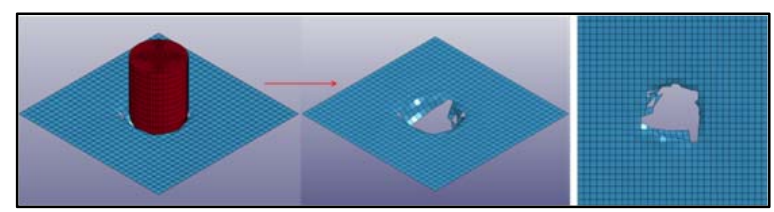

Fig. 32: Facesheet with element formulation 16

In a second step the core and the facesheet have been modeled as a sandwich on assembly level. This model was also correlated by experimental tests. [4]

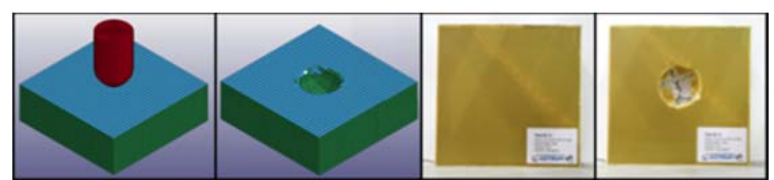

Fig. 33: Assembly level model (left), impact test objects (right) before and after impact

An assessment between hourglass energy, accuracy and CPU time came to the result that element formulation 0 with an element size of $10 \mathrm{~mm}$ and element formulation 1 with an hourglass coefficient of 0.03 are determined as best solutions taking into account the quality of each criterion.

The parameters from assembly level are transferred to the demonstrator level for the model generation. New strain and Young's Modulus values from facesheet tensile tests are implemented into the material card of MAT54, replacing the values of the previous used Kevlar 49.

The model consists of three parts (Fig. 34), firstly the Marslander composed of crushable (1), facesheet (2) and a virtual rigid plate (5) with center of mass (boxed in yellow), secondly the rigid ground (3) and at last a rigid sphere (4) resembling a hemi-spherical stone.

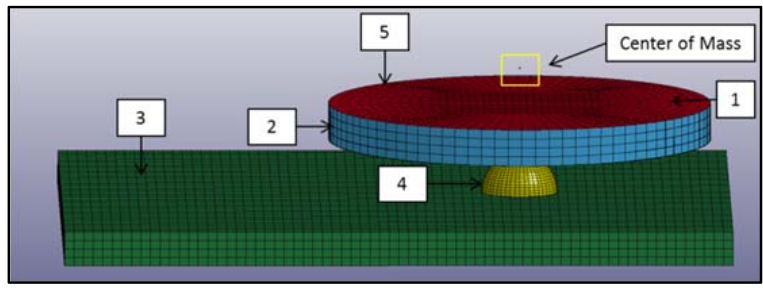

Fig. 34: FEM design of Marslander test setup

The element size on demonstrator level is set to $22 \mathrm{~mm}$ for the solid honeycomb elements, such as the facesheet shell elements. The element size of the sphere is set to be slightly smaller in order to avoid numeric problems during contact. Both parts are assigned rigid material cards and are constrained in all directions within this card.

\section{VI.II. Validation}

Four scenarios are selected for the validation, each represented by one test specimen including its initial conditions and results. The other scenarios had either no sensors (E1, E2) or failed during test (Scenario 3) and are not analyzable.

The validation focused on the motion behavior, the comparison of real and simulated forces on the platform and the final deformation of the honeycomb, as seen in Fig. 35 and Table 6. 


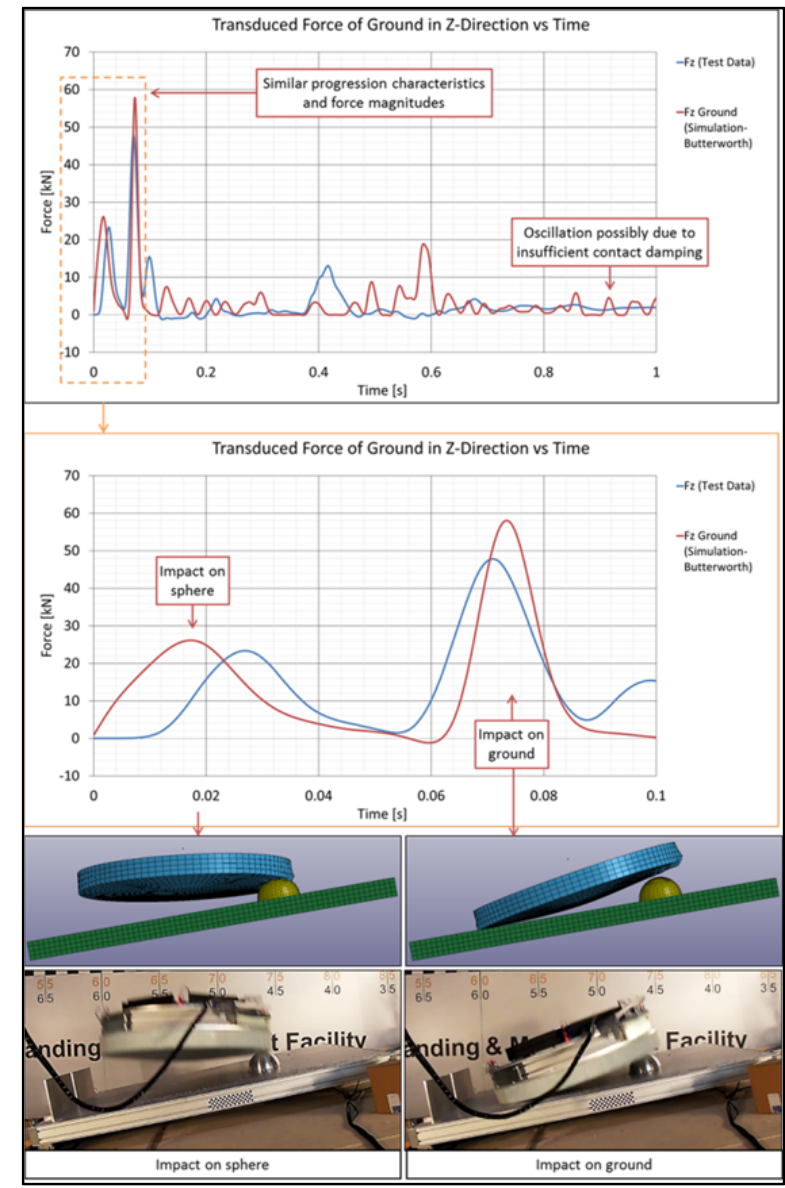

Fig. 35: Comparison of transduced z-force between test and simulation data for Scenario 4

In Fig. 35 the tested against the simulated force is presented. Only slight differences occur to the real test, caused by different touchdown motion, in which the simulated platform generates a larger tilting angle. This behavior could possibly be caused by insufficient contact damping, which is a general observation of the validation. As in all scenarios the max force peak is higher than the tested one, which suspects that the facesheet fails too early in the simulation. This is also the reason, why all simulated penetration depths are larger than the tested ones. Further adaption of the facesheet material card and contact damping has to be done for verification.

\begin{tabular}{|c|c|c|c|c|}
\hline Scenario & $\mathbf{1 A}$ & 2 & $1 B$ & 4 \\
\hline \multicolumn{5}{|l|}{ Test } \\
\hline \begin{tabular}{|c|} 
Penetra- \\
tion depth
\end{tabular} & $59.2 \mathrm{~mm}$ & $0 \mathrm{~mm}$ & $59.2 \mathrm{~mm}$ & $16 \mathrm{~mm}$ \\
\hline \multicolumn{5}{|l|}{$\begin{array}{l}\text { Simu- } \\
\text { lation }\end{array}$} \\
\hline $\begin{array}{l}\text { Penetra- } \\
\text { tion depth }\end{array}$ & $76.2 \mathrm{~mm}$ & $0 \mathrm{~mm}$ & $68.2 \mathrm{~mm}$ & $41 \mathrm{~mm}$ \\
\hline Difference & $\begin{array}{c}17 \mathrm{~mm}= \\
28.7 \%\end{array}$ & $\begin{array}{c}0 \mathrm{~mm}= \\
0 \%\end{array}$ & $\begin{array}{c}10 \mathrm{~mm}= \\
16.9 \%\end{array}$ & $\begin{array}{c}25 \mathrm{~mm}= \\
156 \%\end{array}$ \\
\hline $\begin{array}{c}\text { Analogy } \\
\text { of Data }\end{array}$ & $\begin{array}{c}\text { semi- } \\
\text { accurate }\end{array}$ & inaccurate & accurate & accurate \\
\hline \begin{tabular}{|c|} 
Total \\
CPU time
\end{tabular} & $1 \mathrm{~h} 25 \mathrm{~min}$ & $1 \mathrm{~h} 39 \mathrm{~min}$ & $1 \mathrm{~h} 37 \mathrm{~min}$ & $1 \mathrm{~h} 2 \mathrm{~min}$ \\
\hline
\end{tabular}

Table 6: Comparison of deformation between test and simulation

The validation of the test cases $1 \mathrm{~A}, 1 \mathrm{~B}$ and 4 have shown reasonable results with similar deformation patterns, penetration depths and force progression. Additionally, the ending static force values were identical with respect to test data. The correct point of facesheet failure, identified by the first force peak, was only realized for Scenario $1 \mathrm{~B}$, in which vertical and horizontal touchdown velocity components were present. The touchdown motions of the simulations have exhibited slightly stronger rebounds, assumingly caused by insufficient contact damping, as a remaining oscillation is visible in all cases. An exception was observed in Scenario 2, a horizontal impact onto a flat ground. Beside the minor deformation of the platform, all other characteristics such as touchdown motion or force and acceleration data have not shown any correlation whatsoever, caused by lower damping propagation.

\section{CONCLUSION \& OUTLOOK}

Both the simulation and the experimental testing have proven the system design of a stable lander concept without landing legs. The test setup could deliver the lander to the designated touchdown point at the right velocity.

No critical lander damages appeared during all tests of the diverse scenarios. Although no stability tests (prevention of toppling over) have been performed, the 
platform showed a stable behavior in every situation. The surface platform showed flection under the load of impact, which needs to be studied in more detail.

The simulations show a moderate conservative behavior in comparison to the tested platforms. In all cases the simulated penetration depth is greater than in reality, and the maximum force and acceleration values are slightly higher. The conservative character is important for the design of such a platform, as in this way, one knows that the platform will always be less damaged by the impact than predicted by the simulation.

The results of this project are able to provide a prediction of touchdown cases for a landing platform using a sandwich structure with an aluminum honeycomb as shock and energy absorber. However uncertainties have been observed within the facesheet behavior, especially when loaded out of plane, or perpendicularly. These effects require further attention, possibly by additional material tests focusing on compressive and impact properties. A parameter study of the facesheet material model could be conducted in parallel, simulating the failure modes at impact. The improvement of the facesheet material card could effectively lead to a more accurate touchdown behavior of the overall platform.

For actual mission designs, further tests regarding shock values are necessary to ensure the functionality of instruments, installed upon the landing platform.

\section{REFERENCES}

[1] Top HD Photos Gallery, http://www.tophdgallery.com, September, 2015

[2] Ulamec, S. and Biele J., Surface elements and landing strategies for small bodies missions Philae and beyond, Advances in Space Research, Vol. 44, pp.847-858, 2009

[3] ESA, http://exploration.esa.int/mars/47852entry-descent-and-landing-demonstratormodule/, September 2015

[4] Reinhardt, B., Experimental Investigation and Evaluation of the Crash Behaviour of a Planetary Landing Platform Using Crushable Layers of Aluminum Honeycomb, Bachelor Thesis at University of Bremen, 2012

[5] Fibre institute Bremen e.V. (FIBRE), German Aerospace Center (DLR), Fibretech composites $\mathrm{GmbH}$, Astrium GmbH, Entwicklung, Fertigung und Test eines Marslandekonzeptes in Sandwichbauweise, project report, Bremen, Germany, July 2013

[6] Schröder, S., Applications for a gravity compensating test facility for planetary surface mobility, DLRK, 2011
[7] Reinhardt, B., Touchdown Simulation, Testing and Validation of a Marslander Demonstrator, Master Thesis at University of Bremen, 2014

[8] Reinhardt, B., et.al, Touchdown Simulation, Testing and Validation of a Marslander Demonstrator, $66^{\text {th }}$ IAC, 2015

[9] Knappe, Verena, Correlation and Evaluation of a Finite Element Model using Solid Elements for the Virtual Testing of the Touchdown Behaviour of a Robotic Landing Platform with a Crushable Shock Absorber. Diploma Thesis, RWTH Aachen, August 2013

[10] Kojima, S., A study on Yielding Function of Aluminum Honeycomb, 5th European LS-Dyna Users Conference, Honeycomb and Barrier. Birmingham, UK, May 2005

[11] Bala, S., Day, J., General Guidelines for Crash Analysis in LS-Dyna, Livermore Software Technology Corporation 